\title{
ANALISIS JARINGAN AKSES INTERNET MENGGUNAKAN MIKROTIK ROUTER OS DI SMK TUNAS HARAPAN DENGAN OPTIMALISASI LOAD BALANCING MENGGUNAKAN PARAMETER QoS (Quality of Service)
}

\author{
Daud Muhammad Tulloh ${ }^{1}$, M. Ficky Duskarnaen, ST, M.Sc ${ }^{2}$, Hamidillah Ajie, S.Si., MT \\ ${ }^{1}$ Mahasiswa Prodi PendidikanTeknik Informatika dan Komputer, Teknik Elektro, FT - UNJ \\ ${ }^{2,3}$ Dosen Prodi Pendidikan Teknik Informatika dan Komputer, Teknik Elektro, FT - UNJ

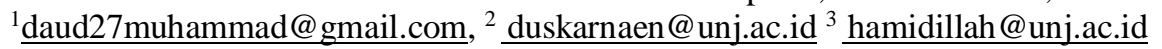

\begin{abstract}
Abstrak
Penelitian ini bertujuan untuk mengetahui quality of service jaringan akses Internet dengan optimalisasi load balance pada Mikrotik Router OS di SMK Tunas Harapan Jakarta. Penelitian ini menggunakan metode penelitian rekayasa teknik dengan metode pengembangan sistem NDLC (Network Development Life Cycle), tahap implementasi sampai pada tahapan pengukuran meliputi throughput, jitter, packet loss, dan delay dengan melakukan transfer data dan monitoring streaming dari laptop client ke server serta penerapan load balancing untuk optimalisasi dua ISP. Berdasarkan hasil akhir dari analisis dapat simpulkan bahwa kinerja parameter quality of service yaitu throughput, jitter, packet loss, dan delay pada jaringan akses Internet SMK Tunas Harapan termasuk dalam kategori Kurang Memuaskan menurut TIPHON.
\end{abstract}

Kata kunci : Throughput, ISP, Load Balancing, dan Mikrotik.

\section{Pendahuluan}

Kebutuhan internet di SMK Tunas Harapan secara optimal selalu diupayakan. Terbukti dengan dibangunnya infrastruktur jaringan berbasis LAN (Local Area Network) pada Lab TKJ, Lab KKPI, Ruang Wakasek, Ruang Guru, Ruang Kepala Sekolah, dan Ruang Tata Usaha. Selain itu, upaya pemerataan sinyal wifi (Coverage Area) agar bisa menjangkau semua ruangan guna mendukung proses pembelajaran juga terus dilakukan. Dengan luas total lahan $6.000 \mathrm{~m}^{2}$ penggunaan kabel jaringan untuk menjangkau 25 ruang kelas dengan sebagian kelas berlantai 3 dirasa kurang efektif.

Untuk saat ini topologi dari suatu jaringan LAN umumnya menggunakan topologi star (bintang) yaitu mempunyai banyak client yang dihubungkan ke satu server atau switch. Oleh karena itu tidak menutup kemungkinan, client akan mengalami kepadatan jalur transfer data atau akses Internet yang tidak lancar. Untuk dapat menggunakan layanan Internet kita dapat menghubungi penyedia jasa layananan Internet dengan berbagai operator berbeda.

Berdasarkan latar belakang masalah yang ada, maka dilakukan penelitian dengan judul analisis jaringan akses Internet menggunakan mikrotik routerOS dengan optimalisasi load balancing di SMK Tunas Harapan menggunakan parameter QoS (quality of service)".

Dengan analisis QoS jaringan Internet di SMK Tunas Harapan maka dapat memudahkan para siswa, guru maupun karyawan untuk mengakses
Internet. Pengimplementasian load balancing pada Mikrotik agar dapat lebih efektif dalam menyetarakan beban trafik koneksi pada jalur koneksi Internet dan menyelesaikan masalah kecepatan akses Internet dan koneksi yang tidak stabil dengan menggunakan dua koneksi Internet.

\section{Dasar Teori}

\subsection{Load Balancing}

Load Balancing adalah teknik untuk mendistribusikan beban trafik pada dua atau lebih jalur koneksi secara seimbang, agar trafik dapat berjalan optimal, memaksimalkan throughput, memperkecil waktu tanggap dan menghindari overload pada salah satu jalur koneksi. (Dewobroto: 2009).

\subsection{Qos (Quality of Service)}

Merupakan metode pengukuran seberapa baik jaringan yang sudah diterapkan dan digunakan untuk membantu administrator dengan memastikan bahwa klien mendapatkan kinerja yang handal dari aplikasi-aplikasi berbasis jaringan. Pada jaringan berbasis IP, IP QoS mengacu pada performa dari paket-paket IP yang lewat melalui satu atau lebih jaringan.

\section{Parameter QoS}

Pada QoS terdapat beberapa komponen yaitu :

- Delay merupakan total waktu yang dilalui suatu paket dari pengirim ke penerima 
dalam jaringan. Delay pada dasarnya tersusun atas latency, delay akses, serta delay transmisi.

Tabel 2. 1 Kategori Delay (Latency)

\begin{tabular}{|c|c|c|}
\hline $\begin{array}{c}\text { Kategori } \\
\text { Latensi }\end{array}$ & Besar Delay & Indeks \\
\hline Sangat Bagus & $<150 \mathrm{~ms}$ & 4 \\
\hline Bagus & $150 \mathrm{~ms} \mathrm{~s} / \mathrm{d} 300 \mathrm{~ms}$ & 3 \\
\hline Sedang & $300 \mathrm{~ms} \mathrm{~s} / \mathrm{d} 450 \mathrm{~ms}$ & 2 \\
\hline Jelek & $\square 450 \mathrm{~ms}$ & 1 \\
\hline \multicolumn{3}{|c|}{ (sumber: TIPHON) } \\
\hline
\end{tabular}

- Jitter merupakan perbedaan waktu kedatangan dari suatu paket ke penerima dengan waktu yang diharapkan. Jitter dapat menyebabkan sampling di sisi penerima menjadi tidak tepat sasaran, sehingga informasi menjadi rusak.

Tabel 2. 2 Kategori Jitter

\begin{tabular}{|c|c|c|}
\hline Kategori Jitter & Jitter & Indeks \\
\hline Sangat Bagus & $0 \mathrm{~ms}$ & 4 \\
\hline Bagus & $0 \mathrm{~ms} \mathrm{~s} / \mathrm{d} 75 \mathrm{~ms}$ & 3 \\
\hline Sedang & $75 \mathrm{~ms} \mathrm{~s} / \mathrm{d} 125 \mathrm{~ms}$ & 2 \\
\hline Jelek & $125 \mathrm{~ms} \mathrm{~s} / \mathrm{d} 225 \mathrm{~ms}$ & 1 \\
\hline \multicolumn{3}{|c|}{ (sumber: TIPHON) }
\end{tabular}

- Throughput yaitu kecepatan (rate) transfer data efektif, yang diukur dalam Bps (byte per second). Aktual bandwidth dapat dihitung dengan melihat jumlah throughput dibagi dengan jumlah paket yang datang terhadap yang dikirim. Aktual bandwidth adalah total bandwidth yang tersedia dibagi dengan bandwidth total yang dapat dihitung dengan:

\section{Tabel 2.3 Kategori Throughput}

\begin{tabular}{|c|c|c|}
\hline $\begin{array}{c}\text { Kategori } \\
\text { Throughput }\end{array}$ & Throughput & Indeks \\
\hline Sangat Bagus & 100 & 4 \\
\hline Bagus & 75 & 3 \\
\hline Sedang & 50 & 2 \\
\hline Jelek & $<25$ & 1 \\
\hline \multicolumn{2}{|c|}{ (sumber: TIPHON) } \\
\hline
\end{tabular}

- Packet Loss adalah ukuran error rate dari transmisi paket data yang diukur dalam persen yang dapat disebabkan oleh sejumlah faktor, mencakup penurunan signal dalam media jaringan, melebihi batas saturasi jaringan, paket yang corrupt yang menolak untuk transit, kesalahan hadware jaringan. Beberapa network transport protokol seperti TCP menyediakan pengiriman paket yang dapat dipercaya. Dalam hal kerugian paket, penerima akan meminta retransmission atau pengiriman secara otomatis.

Tabel 2.4 Kategori Packet Loss

\begin{tabular}{|c|c|c|}
\hline $\begin{array}{c}\text { Kategori } \\
\text { Degredasi }\end{array}$ & $\begin{array}{c}\text { Packet Loss } \\
(\%)\end{array}$ & Indeks \\
\hline Sangat Bagus & 0 & 4 \\
\hline Bagus & 3 & 3 \\
\hline Sedang & 15 & 2 \\
\hline Jelek & 25 & 1 \\
\hline \multicolumn{2}{|c|}{ (sumber : TIPHON) } \\
\end{tabular}

\subsection{Network Development Life Cycle (NDLC)}

Menurut Goldman dan Rawles (2004:470) Network Development Life Cycle (NDLC) adalah metode yang dapat digunakan untuk mengembangkan suatu jaringan komputer. Adapun tahapan yang terdapat dalam metode NDLC adalah sebagai berikut.

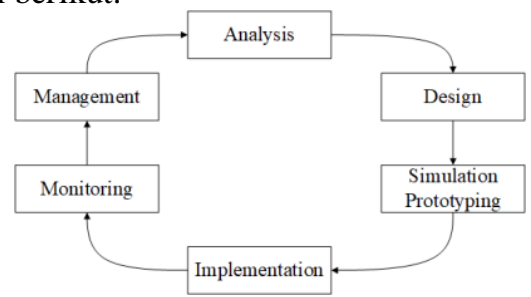

Gambar 2. 1 Network Development Life Cycle

\subsection{Kerangka Berpikir}

Berdasarkan kajian teori yang dilakukan terhadap cakupan jaringan, wilayah pembuatan jaringan hanya lingkup sekolah saja. Maka dalam penelitian ini menggunakan skala jaringan LAN (Local Area Network) menggunakan kabel (wireline). Topologi jaringan yang digunakan adalah topologi star dikarenakan untuk menghubungkan beberapa node ke dalam satu konsentrator dengan menyambungkan beberapa device ke dalam satu switch. Metode pengembangan sistem yang digunakan adalah NDLC (Network Development Life Cycle). Proses pembuatan jaringan akses Internet ini dimulai dengan pengujian untuk mengetahui kualitas akses Internet yang diberikan. Berikut adalah kerangka berpikir pada gambar 2.2. 


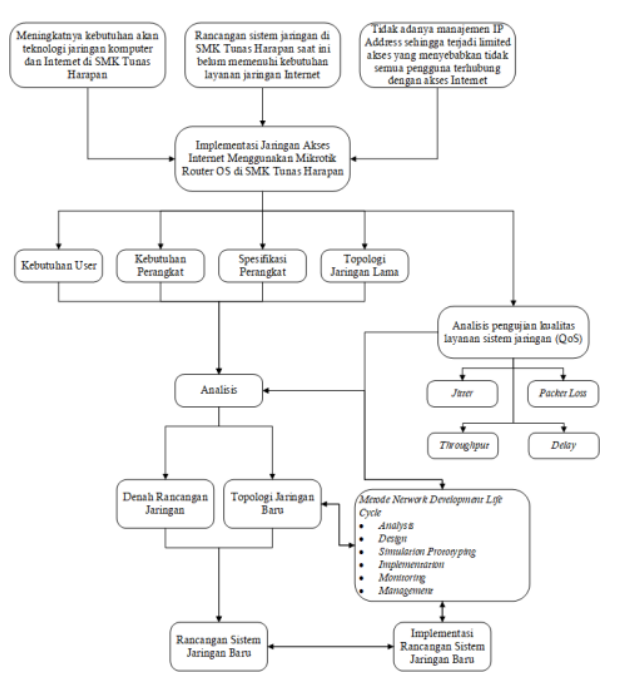

Gambar 2.2 Kerangka Berpikir

\section{Metodologi}

Penelitian dilaksanakan di jaringan wireless dan wireline di SMK Tunas Harapan Jakarta Barat. Waktu penelitian dilaksanakan dari bulan November 2018 sampai bulan Januari 2019.

Penelitian berupa informasi mengenai penerapan load balancing yang dilakukan di jaringan SMK Tunas Harapan Jakarta, pembagian IP address, topologi jaringan wireless, dan pengukuran kinerja parameter QoS (Quality of Service) meliputi delay, jitter, packet loss dan throughput.

Berikut ini adalah metode untuk perancangan desain topologi dan konfigurasi load balancing di SMK Tunas Harapan yang ditunjukkan pada Gambar 3.2

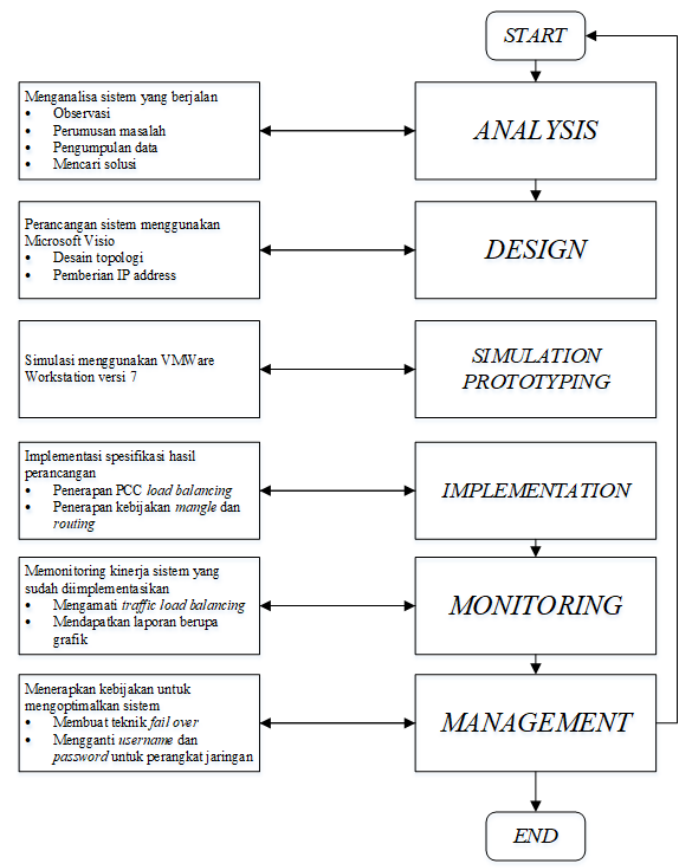

Gambar 3.1 Diagram Alir Penelitian

\section{Hasil dan Analisis}

\subsection{Deskripsi Hasil Penelitian}

Penelitian ini akan dilakukan untuk menganalisis kinerja parameter QoS (Quality of Service) jaringan nirkabel di SMK Tunas Harapan menggunakan software wireshark. Tahap implementasi hanya sampai pada tahapan simulasi pengukuran meliputi delay, jitter, packet loss dan throughput dengan melakukan monitoring dari laptop client ke server secara end to end.

\subsection{Analisis Hasil Penelitian}

Setelah didapat hasil pengujian skenario I dari implementasi topologi baru, maka dapat dibandingkan dengan topologi sistem berjalan yang sudah dilakukan pengujiannya. Berikut adalah perbandingan pengujian topologi sistem berjalan dengan topologi baru.

Tabel 4.1 Pengujian Skenario I

\begin{tabular}{|c|c|c|c|c|c|c|c|c|c|}
\hline \multirow{2}{*}{ Penguluraran } & \multirow{2}{*}{ 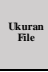 } & \multicolumn{4}{|c|}{ Topalogi Sistem Berjalan } & \multicolumn{4}{|c|}{ Topologi Baru } \\
\hline & & $\begin{array}{c}\text { Dela } \\
\text { (ms) }\end{array}$ & $\begin{array}{c}\text { Jitite } \\
\text { (nms) }\end{array}$ & 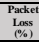 & $\begin{array}{c}\text { Throughpure } \\
\text { I }\end{array}$ & $\begin{array}{l}\text { Delay } \\
\text { (lis) } \\
\end{array}$ & $\begin{array}{l}\text { Jitite } \\
\text { (ins) }\end{array}$ & 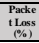 & Through hpet \\
\hline \multirow{3}{*}{ 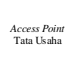 } & $250 \mathrm{Mb}$ & 159. & 7.84 & 0.00 & 39.11 & 159 & 1.66 & 0.00 & 63.98 \\
\hline & $500 \mathrm{Mb}$ & $\begin{array}{l}158 . \\
5\end{array}$ & 5.59 & 0.00 & 64.26 & 74.8 & 1.85 & 0.00 & 45.40 \\
\hline & $1 \mathrm{~Gb}$ & 153 & 7.81 & 0.00 & 66.07 & 95.6 & 7.84 & 0.00 & 61.77 \\
\hline
\end{tabular}

Pengujian data jaringan skenario II pada topologi baru sebelum dan sesudah konfigurasi load balance dilakukan pada saat jam kerja menuju istirahat antara pukul 11.00-12.00. Pengukuran dilakukan dari sisi client yang terhubung langsung ke access point yang diakses oleh user dan memonitoring data dengan membuka aplikasi wireshark. Berikut adalah hasil dari pengujian yang dilakukan pada table 4.2.

Tabel 4.2 Pengujian Skenario II

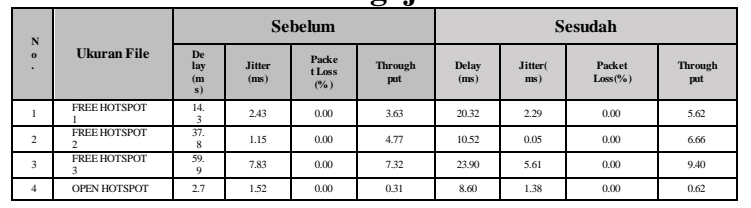

\section{Kesimpulan dan Saran}

\subsection{Kesimpulan}

1. Topologi sistem berjalan dengan topologi baru yang dibuat masih dengan nilai yang sama yaitu 3,25 dengan kategori "kurang memuaskan". Namun terdapat perubahan yang signifikan pada rata-rata waktu yang dibutuhkan data untuk menempuh jarak dari asal ke tujuan (delay) yakni $157 \mathrm{~ms}$ dengan kategori "bagus" pada topologi sistem berjalan dan $109.8 \mathrm{~ms}$ dengan kategori "sangat bagus" pada topologi baru. Hal ini dikarenakan jarak tempuh yang dilalui berkurang pada topologi baru dengan tidak 
melalui beberapa access point.

2. Topologi baru sebelum dan sesudah konfigurasi load balance tidak mengalami perubahan yang berarti dengan kategori "kurang memuaskan".

3. Throughput yang dihasilkan tidak ada perubahan pada pengujian konfigurasi load balance. Hal ini dikarenakan buruknya kualitas saluran, gangguan sinyal (inteferensi), atau saluran yang penuh (overload).

\subsection{Saran}

Berdasarkan kesimpulan-kesimpulan yang telah dikemukakan, dapat diajukan beberapa saran untuk pengembangan lebih lanjut, antara lain:

1. Menambah atau mengganti access point dengan concurrent yang sesuai kebutuhan agar akses Internet yang diberikan dapat digunakan secara optimal.

2. Mengurangi gangguan jaringan eksternal seperti tethering, bluetooth, dan media penghantar sinyal lainnya.

3. Memfungsikan fitur lain dari mikrotik yaitu bandwidth management agar dapat membagi secara rata bandwidth sesuai jumlah client yang aktif.

4. Mengurangi beban trafik jaringan dengan batasan waktu dan penggunaan bandwidth antara guru, staff dan siswa.

5. Dalam pemilihan ISP, diusahakan yang memiliki kualitas bandwidth dan connection speed yang hampir sama agar dalam browsing tidak terjadi koneksi yang lambat dikarenakan response time yang berbeda pada tiap ISP

\section{Daftar Pustaka:}

Abe Wisnu Syaputra, Setiawan Assegaff.(2017).

Analisis Dan Implementasi Load Balancing Dengan Metode Nth Pada Jaringan Dinas Pendidikan Provinsi Jambi.http://jurnalmsi. stikom-.ac.id/index.php/jurnalmsi/article/ view/132/112. Diakses pada tanggal 6 Januari 2019.

Agung Nugroho, 2005. Strategi Jitu memilih Metode statistic Penelitian dengan SPSS, Andi, Jogyakarta.

Athailah. (2013). Mikrotik Untuk Pemula. Jakarta: Mediakita.

Bambang Hariyanto, 2004, Sistem Manajemen Basis Data: Pemodelan,Perancangan,dan

Terapannya, Informatika, Bandung.

Depdikbud. (1995). Kamus Besar Bahasa Indonesia. Jakarta : Balai Pustaka.

Dewobroto, Pujo. (2009). Load Balance menggunakan Metode PCC.http://www. $\underline{\text { mikrotik.co.id/artikel_lihat.php?id=34. }}$
Diakses pada tanggal 3 Januari 2019.

Haryanto, Muhammad Dedy, Riadi, Imam. (2014).

Analisis Dan Optimalisasi Jaringan Menggunakan Teknik Load Balancing (Studi Kasus : Jaringan UAD Kampus3). https://media.neliti.com/media/publication 1210977analisis-danoptimalisasi-jaringan mengg.pdf. Diakses pada tanggal 8 Desember 2018.

I Putu Agus Eka Pratama dan Sinung Suakanto. (2015). Wireless Sensor Network. Bandung: Penerbit Bandung.

Kementrian Riset Teknologi dan Pendidikan Tinggi. (2017). Pedoman Penyelenggaraan Pendidikan Profesi Guru. Jakarta.

Lammle, Todd., 2004, Cisco Certified Network Associate Study Guide, Elex Media Komputindo, Jakarta. 